\title{
In Hospital Outcome of Myocardial Infarcton in Nondiabetic Patients with High on Admission Blood Glucose Level
}

\author{
M Ullah, LA Sayami, MR Khan, A Jahan, Z Rahman, MT Rahman, AAS Majumder \\ Department of Cardiology, NICVD, Dhaka.
}

Keywords:

STEMI, NSTEMI, Blood

glucose.

\begin{abstract}
Background: Patients without a history of diabetes often develop hyperglycemia during an acute coronary syndrome (ACS). Our aim was to evaluate the impact of admission hyperglycemia on in hospital outcome of non-diabetic patients admitted for acute coronary syndromes.

Methods: The retrospective study was conducted in National Institute of Cardiovascular Diseases among the patients with acute myocardial infarction without history of diabetes. 50 patients with ST elevation MI (STEMI) with complications, 50 patients with STEMI without complications, 50 patients with non-ST elevation MI (NSTEMI) with complications and 50 patients without complications were included in the study. Every patient got the treatment as per protocol of the institute. On admission blood glucose of the patients was recorded. Level of blood glucose was correlated with the frequency of complications.

Results : Average on admission blood sugar level was higher in patients who developed complications with STEMI (11.4 vs $8.78 \mathrm{mmol} / \mathrm{L}$ ). On admission blood sugar level was also significantly higher in patients with NSTEMI with complications (10.6 vs $8.6 \mathrm{mmol} / \mathrm{L})$. The frequency of individual complications had no significant relation with the blood sugar level.

Conclusion : Higher level of admission blood glucose is related to poor in hospital outcome in both STEMI \& NSTEMI even in nondiabetic patients. It may be used as a predictor of poor outcome of patients with myocardial infarction.
\end{abstract}

(Cardiovasc. j. 2011; 3(2): 143-148)

\section{Introduction:}

The reported prevalence of hyperglycaemia among those with acute coronary syndrome (ACS) varies widely. An early series reported $20 \%$ of patients with acute myocardial infarction (AMI) presenting with plasma glucose $>11.0 \mathrm{mmol} / \mathrm{l}^{1}$ Hyperglycaemia remains common even after excluding diabetic individuals. Of 38864 nondiabetic patients with troponin-positive ACS admitted to hospitals in England and Wales, 9.9\% presented with blood glucose $>11.1 \mathrm{mmol} / \mathrm{l},{ }^{2}$ and of 1604 non-diabetic patients admitted to French hospitals, $16.4 \%$ presented with blood glucose 7.9 $9.3 \mathrm{mmol} / \mathrm{l}$ and $16.7 \%$ presented with blood glucose $.9 .3 \mathrm{mmol} / \mathrm{l}^{3}$

In a systematic review of 15 studies (1966-1998) on AMI, the association of hyperglycaemia with increased in-hospital mortality was stronger in non-diabetic patients than in diabetic patients. ${ }^{4}$ Hyperglycaemia at presentation, while often reflecting undiagnosed and persisting abnormalities of glucose handling, may also represent a transient stress response mediated through the autonomic nervous system with release of catecholamines and adrenal corticosteroids. ${ }^{5}$

This catecholamine response occurs early, is restricted to the first five days and is proportional to the size of infarction - being associated with faster heart rate, poorer Killip class and lower ejection fraction on discharge. ${ }^{6,7}$ Hyperglycaemia has been labeled an "epiphenomenon"-a marker of larger infarction and poorer left ventricular function-being associated with larger infarcts, $, 8,9$ heart failure on admission5 and elevated brain natriuretic peptide. ${ }^{10}$

On the other hand whatever the cause of hyperglycaemia in acute myocardial infarction, it has got a detrimental effect on myocardium itself. Effects of hyperglycaemia include the promotion 
of oxidative stress, impairment of endothelial function, promotion of coagulation, non-enzymatic glycation of platelet glycoproteins with abrupt changes in aggregability, amplification of inflammation (with adverse effects most marked in those with coexisting raised inflammatory markers ${ }^{11}$ ), suppression of immunity and direct toxicity to myocytes and promotion of apoptosis. Acute hyperglycaemia has been shown to impair ischaemic preconditioning, attenuate the protective effect of pre-infarction angina on microvascular function ${ }^{12}$ and reduce the effectiveness of collateral blood supply into ischaemic zones. ${ }^{13-16}$

\section{Study population:}

The study was conducted in the National Institute of Cardiovascular Diseases, Dhaka, from June 2010 to August 2010. Two sets of patients who were not previously diagnosed as diabetic were includedSTEMI and NSTEMI. In STEMI group two subsets of patients were included, 50 patients without any in-hospital complications like I) post MI angina, ii) heart failure iii) arrhythmia iv) hypotension v) cardiogenic shock vi) death; and another 50 patients with such complications. All patients were admitted within 12 hours of onset of chest pain and all the patients received thrombolytics. Similarly in NSTEMI group two subsets were selected; 50 patients without above mentioned inhospital complications and 50 patients with such complications. All the patients received treatment as per protocol of the Hospital. On admission blood glucose level of all the patients were collected. On admission blood glucose level of the patients were correlated with the frequency of in hospital outcome of MI in both the groups separately. Whether high admission blood glucose level has an impact on in hospital outcome of STEMI \&
NSTEMI differently was also evaluated.

\section{Results:}

This study was done in the cardiology department of National Institute of Cardiovascular diseases. The study was done to correlate the association of on admission blood glucose level with different complications in patients with no history of diabetes mellitus. The study was conducted in patients with both STEMI and NSTEMI. Smoking, hypertension, diabetes, family history of premature coronary artery disease and dyslipidaemia was present in $66 \%, 44 \%, 8 \%$ and $2 \%$ patients with STEMI with complications. The prevalence of these risk factors was $62 \%, 50 \%, 16 \%$ and $6 \%$ respectively in patients with STEMI without complications. There was no significant difference in the frequency of these risk factors among the patients with STEMI in relation to incidence of complications. Similarly in patients with NSTEMI the prevalence of the risk factors was $72 \%, 56 \%, 16 \%, 8 \%$ in patients with complications; and $60 \%, 52 \%, 12 \%, 08 \%$ in patients without complications. So the distribution of risk factors was almost similar in patients with or without complications.

The average age of the patients with STEMI was 56.6 yrs in patients with complications and 54.9 yrs in patients without any complications. It was 60.7 in patients with NSTEMI with complication and 58.5 in patients without complications. $84 \%$ of patients with STEMI \& complication was male and $78 \%$ of uncomplicated patients with STEMI was female. $70 \%$ of complicated patients with STEMI was male and $78 \%$ of uncomplicated patients with NSTEMI was male. Patients with STEMI who developed complications appeared later in the hospital in relation to those who didn't develop complication (9.3 hrs vs 6.8 ); but it was not

Table-I

Correlation of risk factors with complications of STEMI \& NSTEMI

\begin{tabular}{lcccccc}
\hline Parameters & $\begin{array}{c}\text { STEMI with } \\
\text { complication }\end{array}$ & $\begin{array}{c}\text { STEMI } \\
\text { without } \\
\text { complication }\end{array}$ & p-value & $\begin{array}{c}\text { NSTEMI } \\
\text { with } \\
\text { complication }\end{array}$ & $\begin{array}{c}\text { NSTEMI } \\
\text { without } \\
\text { complication }\end{array}$ & p-value \\
\hline HTN & 22 & 25 & .689 & 28 & 26 & .562 \\
Smoking & 30 & 31 & .500 & 36 & 30 & .086 \\
Dyslipidaemia & 01 & 03 & .617 & 06 & 04 & .715 \\
Family history & 04 & 08 & .357 & 08 & 06 & .356 \\
\hline
\end{tabular}


statistically significant. Similarly patients with NSTEMI who presented later in the hospital had complications (11.2 vs $9.4 \mathrm{hrs}$ ), but it was not also statistically significant. Serum creatinine and serum sodium level was similar in all the groups.

Patients were received drugs as per protocol of the institute. Nitrate, calcium channel blocker, ACE inhibitor and angiotensin receptor blocker had no effect on the incidence of complications. But betablocker significantly reduced the complication rate both in STEMI and NSTEMI.

Average on admission blood sugar level was higher in patients who developed complications with STEMI (11.4 vs $8.78 \mathrm{mmol} / \mathrm{L}$ ). On admission blood sugar level was also significantly higher in patients with NSTEMI with complications (10.6 vs $8.6 \mathrm{mmol} /$ L). The frequency of individual complications had no significant relation with the blood sugar level.

Table-II

Correlation of age, sex and renal function with complications of STEMI \& NSTEMI

\begin{tabular}{|c|c|c|c|c|c|c|}
\hline$\overline{\text { Parameters }}$ & $\begin{array}{l}\text { STEMI with } \\
\text { complication }\end{array}$ & $\begin{array}{c}\text { STEMI } \\
\text { without } \\
\text { complication }\end{array}$ & $\mathrm{p}$-value & $\begin{array}{c}\text { NSTEMI } \\
\text { with } \\
\text { complication }\end{array}$ & $\begin{array}{c}\text { NSTEMI } \\
\text { without } \\
\text { complication }\end{array}$ & p-value \\
\hline$\overline{\text { Age (years) }}$ & 56.6 & 54.9 & .463 & 60.7 & 58.5 & .634 \\
\hline $\operatorname{Sex}(M / F)$ & $42 \quad 08$ & $39 \quad 11$ & .611 & $35 \quad 15$ & 39 & .495 \\
\hline $\begin{array}{l}\text { Duration of chest } \\
\text { pain(hours) }\end{array}$ & 9.3 & 6.8 & .150 & 11.2 & 9.4 & .080 \\
\hline
\end{tabular}

Table-III

Correlation of drugs used with complications of STEMI \& NSTEMI

\begin{tabular}{lcccccc}
\hline Parameters & $\begin{array}{c}\text { STEMI with } \\
\text { complication }\end{array}$ & $\begin{array}{c}\text { STEMI } \\
\text { without } \\
\text { complication }\end{array}$ & p-value & $\begin{array}{c}\text { NSTEMI } \\
\text { with } \\
\text { complication }\end{array}$ & $\begin{array}{c}\text { NSTEMI } \\
\text { without } \\
\text { complication }\end{array}$ & p-value \\
\hline Aspirin & 50 & 50 & - & 50 & 50 & - \\
Clopidogrel & 50 & 50 & - & 48 & 49 & 1.0 \\
Nitrate & 42 & 32 & .039 & 42 & 45 & .06 \\
CCB & 10 & 00 & .360 & 1 & 4 & .36 \\
ACE inhibitor & 17 & 10 & .063 & 10 & 12 & 0.8 \\
ARB & 02 & 02 & 1.00 & 0 & 1 & 1.0 \\
Beta blocker & 21 & 41 & .0003 & 22 & 33 & .016 \\
Serum creatinine (mg/dl) & 1.5 & 1.2 & .128 & 1.15 & 1.08 & .078 \\
Serum sodium level (mmol/L) & 135 & 136 & .331 & 135.3 & 136.2 & .532 \\
\hline
\end{tabular}

Table-IV

Correlation of RBS with complications of STEMI \& NSTEMI

\begin{tabular}{lcccccc}
\hline Parameters & $\begin{array}{c}\text { STEMI with } \\
\text { complication }\end{array}$ & $\begin{array}{c}\text { STEMI } \\
\text { without } \\
\text { complication }\end{array}$ & p-value & $\begin{array}{c}\text { NSTEMI } \\
\text { with } \\
\text { complication }\end{array}$ & $\begin{array}{c}\text { NSTEMI } \\
\text { without } \\
\text { complication }\end{array}$ & p-value \\
\hline $\begin{array}{l}\text { Random blood } \\
\text { sugar }(\mathrm{mmol} / \mathrm{L})\end{array}$ & 11.4 & 8.78 & 0.05 & 10.6 & 8.6 & .004 \\
\hline
\end{tabular}




\section{Discussion:}

This study evaluated the effect of on admission hyperglycaemia in patients with both NSTEMI \& STEMI. The average age of the patients with STEMI was 56.6 yrs and 54.9 yrs in patients with and without complications respectively. Similarly the average age of the patients with NSTEMI with and without complications was $60.7 \& 58.5$ respectively. This is consistent with the other studies involving the MI patients in our institute. ${ }^{17}$ The age distribution of the patients in different groups was similar. In all the groups male patients were predominant. This was because of the more male patient number admitted in the hospital.

The frequency of different risk factors in study population was also comparable with other studies conducted in recent times. The risk factor distribution was almost similar in different groups. ${ }^{18}$ Smoking was the most prevalent one followed by hypertension, dyslipidaemia and family history of coronary heart disease. These risk factors had no significant relation with the rate of complications. Probably a larger number of study population may had a different result. Patients who presented later had more complications in the setting of both STEMI and NSTEMI. But it was not statistically significant. It happened such as the patients who presented more than 12 hours after onset of chest pain were excluded from the study.

All the patients were treated with the drugs as per protocol of the institute. Beta-blocker was used more frequently in the patients with STEMI and NSTEMI patients who had no complications. There was no correlation of other drugs with the frequency of complications.

Complications like post Mi angina, heart failure, arrhythmia, hypotension, shock and death was recorded in the study. The patients who had NSTEMI and had any one of these complications were with higher on admission blood glucose level. Similarly patients STEMI and complications had higher on admission blood glucose level. But the blood glucose had no specific relation with any of the specific complication. Artur et al demonstrated that in hospital mortality was higher in patients with NSTEMI treated conservatively. ${ }^{19}$ Belen CidAlvarez et al also showed that patients with ACS who are not known to suffer from diabetes, admission and fasting blood glucose are both strong predictors of mortality. They also mentioned that the predictive values of admission and fasting blood glucose are similar for forecast times of up to about 1 year, but the better predictor of long term mortality is fasting blood glucose level. ${ }^{20}$

Our study results are similar to the meta-analysis made by Angeli $\mathrm{F}$ et al. ${ }^{21}$ They concluded that in patients without a prior diagnosis of diabetes who are admitted to hospital for ACS, NH increases the risk of both short and long-term mortality.

In one study Carpentier et $\mathrm{al}^{22}$ on admission blood glucose level as a risk factor in the evaluation of chest pain in the emergency department. They concluded that a blood glucose level $>140 \mathrm{mg} / \mathrm{dl}$ in patients admitted to an emergency department for chest pain is associated with non-ST elevation ACS. In another study J Sala et $\mathrm{al}^{23}$ defined the blood glucose level increasing the risk is $6.67 \mathrm{mmol} / \mathrm{L}$. Higher 28 day mortality was observed among MI patients with glycaemia on admission $>6.67 \mathrm{mmol} /$ l compared with patients with lower levels, independently of major confounding variables and, particularly, previous diagnosis of diabetes.

Our study results are consistent with findings of other similar studies which have shown that in STEMI, admission hyperglycaemia independently is associated with incomplete resolution of STsegment elevation, ${ }^{24}$ persisting occlusion of the infarct-related artery after thrombolytic treatment ${ }^{25}$ and (unlike HbA1c or previous diagnosis of diabetes) predicts poor flow in this artery before, ${ }^{26}$ and poorer myocardial perfusion and ST-segment resolution after, successful primary PCI. ${ }^{27-29}$

In the Hellenic Heart Failure Study Serum glucose level at hospital admission correlates with left ventricular systolic dysfunction in nondiabetic, acute coronary patients. Study revealed that a 10 $\mathrm{mg} / \mathrm{dl}$ difference in glucose levels was independently associated with 8\% (95\% confidence interval 2\%-14\%) higher likelihood of left ventricular systolic dysfunction. ${ }^{30}$

Whether hyperglycemia is a mediator or marker of adverse outcomes remains unclear. In any patient, diabetic or not, elevated glucose during AMI could in part reflect the severity of illness resulting from a high catecholamine state and 
increased circulating concentrations of other factors, such as cortisol. On the other hand, Higher glucose levels in patients with AMI have been associated with higher free fatty acid concentrations, insulin resistance, and impaired myocardial glucose use, thus increasing the consumption of oxygen and potentially worsening ischemia. ${ }^{31,32}$

Another possible explanation is that these patients are truly diabetic. As a few small reports have suggested that between $25 \%$ and $70 \%$ of these patients may in fact have undiagnosed diabetes. ${ }^{33,34,35}$ Another explanation is that substantial proportion of hyperglycemic patients without a history of diabetes had at least an underlying insulin resistance, which may have conferred higher risk of mortality, as suggested by others. ${ }^{36}$

Our findings highlight an important potential opportunity to improve care and outcomes for hyperglycemic AMI patients without known diabetes. Experience in other patient populations ${ }^{37}$ indicates that tight glycemic control with insulin therapy during hospitalization may be at least as important for these patients as in diabetics. ${ }^{38}$ Large-scale randomized clinical trials are needed to definitively establish the utility of target-driven aggressive glucose control in this patient group. Our results suggest that these trials should use a target glucose of $110 \mathrm{mg} / \mathrm{dL}$ and are in agreement with the recent statements by the American Diabetes Association and American College of Endocrinology on in-hospital glucose management. ${ }^{39,40}$

\section{Conclusion:}

Higher level of admission blood glucose is related to poor in hospital outcome in both STEMI \& NSTEMI even in nondiabetic patients. It may be used as a predictor of poor outcome of patients with myocardial infarction. This early, simple, and inexpensive marker of bad prognosis after MI should prompt the application of more aggressive treatment of MI and risk factors and, probably of hyperglycaemia during admission.

\section{References:}

1. Oswald GA, Yudkin JS. Hyperglycaemia following acute myocardial infarction: the contribution of undiagnosed diabetes. Diabetes Med 1987;4:68-70.
2. Weston C, Walker L, Birkhead J. Early impact of insulin treatment on mortality for hyperglycaemic patients without known diabetes who present with acute coronary syndrome. Heart 2007;93:1542-6.

3. Kadri Z, Danchin N, Vaur L, et al. Major impact of admission glycaemia on 30 day and one year mortality in non-diabetic patients admitted for myocardial infarction: results from the nationwide French USIC 2000 study. Heart 2006;92:910-5.

4. Capes S, Hunt D, Malmberg K, et al. Stress hyperglycaemia and increased risk of death after myocardial infarction in patients with and without diabetes: a systematic overview. Lancet 2000;355:7738.

5. Oswald GA, Smith CCT, Betteridge DJ, et al. Determinants and importance of stress hyperglycaemia in non-diabetic patients with myocardial infarction. BMJ 1986;293:917-22.

6. Karlsberg RP, Cryer PE, Roberts R. Serial plama catecholamine response in the early course of acute myocardial infarction: relationship to infarct extent and mortality. Am Heart J 1981;102:24-9.

7. Petersen CL, Nielsen JR, Petersen BL, et al. Catecholamine activation in acute myocardial infarction: time course and relation to left ventricular performance. Cardiology 2003;100:23-8.

8. Timmer JR, van der Horst IC, Ottervanger JP, et al. Prognostic value of admission glucose in non-diabetic patients with myocardial infarction. Am Heart $J$ 2004;148:399-404.

9. Meier JJ, Deifuss S, Klaman A, et al. Plasma glucose at hospital admission and previous metabolic control determine myocardial infarct size and survival in patients with and without type 2 diabetes. Diabetes Care 2005;28:2551-3.

10. Bhadriraju S, Ray KK, DeFranco AC, et al. Association between blood glucose and long-term mortality in patients with acute coronary syndromes in the OPUSTIMI 16 Trial. Am J Cardiol 2006;97:1573-7.

11. Ray KK, Cannon CP, Morrow DA, et al. Synergistic relationship between hyperglycaemia and inflammation with respect to clinical outcomes in non-Stelevation acute coronary syndromes: analysis from OPUS-TIMI 16 and TACTICS-TIMI 18. Eur Heart J 2007;28:806-13.

12. Takahashi T, Hiasa Y, Ohara Y, et al. Acute hyperglycaemia prevents the protective effect or preinfarction angina on microvascular function after primary angioplasty for acute myocardial infarction. Heart 2008;94:1402-6.

13. Kersten JR, Toller WG, Gross ER et al. Diabetes abolishes ischemic preconditioning: role of glucose, insulin and osmolality. Am J Physiol Heart Circ Physiol 2000;278:H1218-24.

14. Kersten JR, Toller WG, Tessmer JP, et al. Hyperglycemia reduces coronary collateral blood flow through a nitric oxide-mediated mechanism. Am $J$ Physiol Heart Circ Physiol 2001;281:H2097-104. 
15. Ebel D, Mullenheim J, Frassdorf J, et al. Effect of acute hyperglycaemia and diabetes mellitus with and without short-term insulin treatment on myocardial ischaemic late preconditioning in the rabbit heart in vivo. Pflugers Arch 2003;446:175-82.

16. Ishihara M, Inoue I, Kawagoe T, et al. Effect of acute hyperglycaemia on the ischaemic preconditioning effect of prodromal angina pectoris in patients with a first anterior wall acute myocardial infarction. Am J Cardiol 2003;92:292-4.

17. M Ullah, M Khalequzzaman, SMA Habib, N Kar, MN Islam. Angiographic correlaion of ST segment depression on admission ECG in patients with NSTEMI. Bangladesh Heart Journal 2006; 21(2): 72-77.

18. MA Rahman, MA Ali, AAS Majumder, KMHSS Haque, H Banoo, MA Zaman. Dyslipidaemia and coronary heart disease. Bangladesh Heart Journal 2001; 16(1): 30-35.

19. Artur Dziewierz, Dawid Giszterowicz, Zbigniew Siudak, Tomasz Rakowski, Waldemar Mielecki, Marcin Suska et al. Impact of admission glucose level and presence of Diabetes mellitus on mortality in patients with NSTEMI treated conservatively. Am j Cardiol 2009; 103:954958.

20. Belen Cid- Alvarez, Francisco Gude, Carmen CadarsoSuarez, Eva Gonzales- Babarro, Maria Xose RodriguezAlvaarez, Jose Maria Garcia-acuna et al. admission and fasting plasma glucose for estimating risk of death of diabetic and nondiabetic patients with ACS: nonlinearity of hazard ratios and time- dependent comparison. Am heart J 2009;158:989-97.

21. Angeli F, Verdecchia P, Karthikeyan G, Mazzotta G, Del Pinto M, Repaci S et al. New-onset hyperglycemia and acute coronary syndrome: a systematic overview and meta-analysis. Curr Diabetes Rev 2010 ; 6(2):10210 .

22. Sandrine Charpentier, Maxime Cournot, Dominique Lauque. Usefulness of initial glucose level to improve acute coronary syndrome diagnosis in the emergency department. Emerg Med J 2010. Downloaded from www.emj.bmj.com on September 22, 2010.

23. J Sala, R Masiá, F-J González de Molina, J M FernándezReal, M Gil, D Bosch et al. Short-term mortality of myocardial infarction patients with diabetes or hyperglycaemia during admission. J Epidemiol Community Health 2002;56:707-712.

24. Rasoul S, Ottervanger JP, Bilo HJG, et al. Glucose dysregulation in non-diabetic patients with STelevation myocardial infarction: acute and chronic glucose dysregulation in STEMI. Neth J Med 2007;65:95100.

25. Pinto DS, Kirtane AJ, Pride YB, et al. Association of blood glucose with angiographic and clinical outcomes among patients with ST-segment elevation myocardial infarction (from the CLARITY-TIMI-28 study). Am J Cardiol 2008;101:303-7.

26. Timmer JR, Ottervanger JP, de Boer MJ, et al. Hyperglycemia is an important predictor of impaired coronary flow before reperfusion therapy in STsegment elevation myocardial infarction. $J$ Am Coll Cardiol 2005;45:999-1002.
27. Iwakura K, Ito H, Ikushima M, et al. Association between hyperglycemia and the no reflow phenomenon in patients with acute myocardial infarction. $J$ Am Coll Cardiol 2003;41:1-7.

28. Ishihara M, Kojima S, Sakamoto T, et al. Acute hyperglycemia is associated with adverse outcome after acute myocardial infarction in the coronary intervention era. Am Heart J 2005;150:814-20.

29. Shen XH, Jia SQ, Li HW. The influence of admission glucose on epicardial and microvascular flow after primary angioplasty. Chin Med J (Engl) 2006;119:95102.

30. Chrysohoou C, Pitsavos C, Aggelopoulos P, Skoumas J, Tsiamis E, Panagiotakos DB et al. Serum glucose level at hospital admission correlates with left ventricular systolic dysfunction in nondiabetic, acute coronary patients: the Hellenic Heart Failure Study. Heart Vessels 2010 May; 25(3):209-16.

31. Tansey MJ, Opie LH. Relation between plasma free fatty acids and arrhythmias within the first twelve hours of acute myocardial infarction. Lancet 1983;2:419-422.

32. Oliver MF. Metabolic causes and prevention of ventricular fibrillation during acute coronary syndromes. Am J Med 2002;112:305-311.

33. Oswald GA, Yudkin JS. Hyperglycaemia following acute myocardial infarction: the contribution of undiagnosed diabetes. Diabet Med. 1987; 4:68 -70.

34. Malmberg K. Diabetes, insulin resistance, and the metabolic syndrome in patients with acute myocardial infarction without previously known diabetes. Diabetes Care. 2003;26:2770 -2776.

35. Norhammar A, Tenerz A, Nilsson G, Hamsten A, Efendic $\mathrm{S}$, Ryden L, Malmberg K. Glucose metabolism in patients with acute myocardial infarction and no previous diagnosis of diabetes mellitus: a prospective study. Lancet. 2002;359:2140 -2144.

36. Kragelund C, Snorgaard O, Kober L, Bengtsson B, Ottesen M, Hojberg S, Olesen C, Kjaergaard JJ, Carlsen J, Torp-Petersen C. Hyperinsulinaemia is associated with increased long-term mortality following acute myocardial infarction in non-diabetic patients. Eur Heart J. 2004;25: 1891-1897.

37. van den Berghe G, Wouters P, Weekers F, Verwaest C, Bruyninckx F, Schetz M, Vlasselaers D, Ferdinande P, Lauwers P, Bouillon R. Intensive insulin therapy in the critically ill patients. N Engl J Med. 2001;345: 13591367.

38. Malmberg K, Ryden L, Efendic S, Herlitz J, Nicol P, Waldenstrom A, Wedel H, Welin L. Randomized trial of insulin-glucose infusion followed by subcutaneous insulin treatment in diabetic patients with acute myocardial infarction (DIGAMI study): effects on mortality at 1 year. J Am Coll Cardiol. 1995;26:57- 65.

39. Garber AJ, Moghissi ES, Bransome ED, Clark NG, Clement S, Cobin RH, Furnary AP, Hirsch IB, Levy P, Roberts R, Van den Berghe G, Zamudio V. American College of Endocrinology position statement on inpatient diabetes and metabolic control. Endocr Pract. 2004; $10: 77-82$.

40. Clement S, Braithwaite SS, Magee MF, Ahmann A, Smith EP, Schafer RG, Hirsh IB. Management of diabetes and hyperglycemia in hospitals. Diabetes Care. 2004;27:553-597. 